\title{
Effect of high-fat diet on the various morphological parameters of the ovary
}

\author{
Gören Hilal $^{1}$, Topal Fatma ${ }^{2}$, Yücel Ferruh ${ }^{3}$, Güler Sabire ${ }^{4}$, Aydar Yüksel ${ }^{3}$ \\ ${ }^{1}$ Department of Anatomy, Faculty of Medicine, Duzce University, Duzce, ${ }^{2}$ Department of Medical Services and Techniques, Bilecik Seyh Edebali University, \\ Bilecik, ${ }^{3}$ Department of Anatomy, Medical School of Eskişehir Osmangazi University, Eskişehir, ${ }^{4}$ Department of Histology Embriology, Faculty of \\ Veterinary Medicine, Uludag University, Bursa, Turkey
}

\begin{abstract}
Increased food consumption rich in fat and carbohydrate and sedentary lifestyle have seriously increased the rates of obesity and obesity-associated diseases in developed countries. Female mice with diet-induced obesity exhibit infertility and thus can serve as a model for human polycystic ovary syndrome. The aim of the present study was to examine how ovary is affected by diet-induced obesity. The effects of high-fat diet (HFD) on ovary morphology in mice fed with HFD were investigated using unbiased stereological methods. The ovary of mice fed with HFD ( $\mathrm{n}=8$, C1090-60, Altromine) for 9 weeks, were compared with that of mice fed with standard chow diet ( $\mathrm{n}=8, \mathrm{C} 1090-10$, Altromine). Stereological parameters were obtained in diestrus cycle. The samples were processed through routine and standard paraffin embedding and were serially sectioned in 5- $\mu \mathrm{m}$ thickness then, every 10th section was saved, stained with Crossman's triple stain for counting and measuring. In all sampled sections mean follicle numbers, diameters, total ovarian volume cortex to medulla ratio (Vv), ovum to cell ratio in secondary follicle were examined in all sampled sections. The present results showed that weight of ovarian and amount of intraperitoneal adipose tissue and the body weight markedly increased in obese mice when compared with control groups. Moreover, follicle numbers (except primordial follicles) and diameters were significantly increased in obese mice. Cortex to medulla ratio ( $\mathrm{Vv}$ ) and ovum to cell ratio in secondary follicle were also considerably different between experimental and the control groups. The present findings indicate that obesity adversely affects overall ovarian morphology.
\end{abstract}

Key words: High-fat diet, Morphology, Obesity, Ovary, Stereology

Received April 9, 2019; Revised June 26, 2019; Accepted June 26, 2019

\section{Introduction}

Obesity is a serious worldwide health problem that adversely affects general population and its incidence has been dramatically increasing day by day. According to the World Health Organization (WHO) statistics published in 2013, the frequency of obesity has doubled since 1980 [1]. The WHO's

\footnotetext{
Corresponding author:

Aydar Yüksel (iD

Department of Anatomy, Medical School of Eskișehir Osmangazi University, 26480 Eskişehir, Turkey

Tel: +90-536-650-4433, Fax: +9o-2222393772,

E-mail:yukselaydar@yahoo.com, yaydar@ogu.edu.tr
}

report published in 2016 revealed that more than 1.9 billion adults ( $>18$ years) were overweight and 650 million of them were obese in addition to the presence of 41 million children ( $<5$ years) reported being overweight or obese [1].

Increase in intake of high calorie foods with daily diet not only becomes a dreadful risk factor for developing cardiovascular diseases, diabetes, osteoarthritis, hypertension, cancer, and metabolic disorders but also it is shown to trigger various fertilization problems $[2,3]$. Several earlier studies indicate that abnormal weight gain during childhood and increased amount of fat tissue in the body gradually decreases the age of puberty in females [4-7]. Likewise, previous studies show that adults possessing more than normal fatty tissue suffer from menstrual disorders, anovulation, and infertility problems [8-10]. 
Furthermore, both malnutrition and overeating are shown to harmfully affect fertility in women $[11,12]$. Recent studies disclose that obesity dysregulates the hypothalamic-pituitaryovarian axis and impairs fertilization capacity in humans and animals [13-15]. Obesity is seen more frequently in women than in men and this risk increases with age [16]. Although most obese women are not infertile, obesity is shown to have a hostile effect on their fertility [17]. In their recent study, Brewer and Balen [18] report that obese women are three times more likely to be infertile than women who have a normal body mass index (BMI) since obesity can affect fertilization in many different ways such as incapacitating ovulation and oocyte development. Subsequently, obesity-related reproductive disorders have become a serious problem for both present and future generations as the prevalence of obesity in women of reproductive age are estimated to be at 38.3\% [19].

Obesity is shown to disturb various ovarian functions including polycystic ovarian syndrome (PCOS), an endocrine disorder that adversely affects reproductive life in $6-10 \%$ of women worldwide [20]. PCOS is a health problem that poses a risk for the development of infertility by negatively affecting reproductive functions in women. Moreover, obesity is shown to trigger the emergence of PCOS through adverse changes in fat metabolism. For instance, several studies have shown that insulin resistance develops in women with PCOS, resulting in development of hyperandrogenism, oligo-ovulation/ anovulation, and multiple cysts [21-23], which explains at least in part the mechanism of formation of cystic follicles in obese individuals [24]. High testosterone levels in serum of obese female mice induced by diabetes-associated obesity are demonstrated to be similar to those of women with PCOS [25]. Likewise, prolonged estrous cycles, increase in serum androstenedione and luteinizing hormone levels were also reported in obese animals [26]. Another recent study indicates that not only follicular volume but also conversion of normal follicles to cysts increases during the luteal phase in obese animals. In addition, women with PCOS and obesity are shown to ovulating smaller oocytes than women with normal BMI [27]. On the other hand, PCOS and obesity depending on the BMI are shown to affect the size of oocytes independently of each other in females [28]. Diet-induced obesity leads to pathologies in ovarian function that could include poor oocyte quality, low rates of blastocyst survival, and abnormal embryonic cellular differentiation [29]. Another relevant study demonstrates that ovarian apoptosis particularly increases, oocytes in preovulatory follicles become smaller, and maturation of oocytes declines in obese mice [30].

There are evidence showing that females who are not clinically diagnosed or considered as obese but taking only dietary high-fat foods might develop different types of infertility problems in advance. Therefore, investigation of rate of consumed dietary high-fat foods is critical to reveal the culprit for unexplained infertility problems for the females who have no evident physiological or any other medical reproduction problems $[23,24]$.

Despite many qualitative studies related to obesity and polycystic ovaries in animals and humans are available, the number of quantitative stereological analyzes examining the morphological changes occurring in ovaries of obese animals are limited. Therefore, in the present study we aimed to examine following parameters in ovarian of obese mice using unbiased-stereological methods for quantitative analysis: The parameters included total ovarian weight and its volume, change in the ovarian cortex to medulla ratio, number of follicles, the changes occurring in the mean diameter of follicles, and ratio of ovum to granulosa cell layer in secondary follicle.

\section{Materials and Methods}

\section{Animals and diets}

The mice were obtained from the Medical and Experimental Research Center of Eskişehir Osmangazi University, Eskişehir, Turkey. For the present study, 16 unmated fertile female Swiss albino strains (8-10 weeks old, weighing 22-25 g) were used and they were housed as 4 per cage. The mice were randomly assigned to the control group, which contained 8 mice and fed with standard chow for 9 weeks ( $10 \%$ fat, $n=8, C$ 1090-10, Altromin, Lage, Germany) and high-fat diet (HFD) group, which also contained 8 mice and fed with HFD for 9 weeks (60\% fat, $\mathrm{n}=8, \mathrm{C} 1090-60$, Altromin). The animal cages were maintained at $22^{\circ} \mathrm{C} \pm 2{ }^{\circ} \mathrm{C}$ with a 12 -hour light/12hour dark cycle and the mice were fed with standard or HFD starting from the first day of the experiment and water was provided ad libitum. The treatment of the animals and experimental procedures were approved by the Experimental Animals Ethics Committee of Eskişehir Osmangazi University with the decision numbered 467/2015. The present study was also financially supported by Eskişehir Osmangazi University Research Projects Center with the project code 2014-586. Body weights of the animals were obtained weekly starting from beginning of the experiment to the end of the experiment. Chow diets were kept at $-21^{\circ} \mathrm{C}$ during the experiment 
and the animals were allowed to feed on the diet determined based on maximal amount of daily need. The mice in the control and HFD groups were fed with standard chow and HFDs, respectively during the periods of experiment. While the animals in HFD group received $5.24 \mathrm{kcal}$ from per gram of HFD, in the control group they received $3.52 \mathrm{kcal}$ from per gram of the standard chow.

\section{Determination of estrus cycles}

At the end of the feeding period, vaginal smear method was used to define estrus cycle phase of the mice. Vaginal smear cells taken from animals by sterile swabs were examined under light microscope and the presence of a predominance of nucleated epithelial cells designated as proestrus, existence of primarily anucleated cornified cells defined as estrus, presence of the same proportion among leukocytes, cornified, and nucleated epithelial cells was defined as metestrus, and the occurrence of a primary predominance of leukocytes was defined as diestrus.

\section{Preparation of the ovarian sections}

The mice in diestrus phase were sacrificed by cervical dislocation under general anesthesia delivered with intraperitoneal injection of xylazine at $80 \mathrm{mg} / \mathrm{kg}$ and ketamine at $15 \mathrm{mg} / \mathrm{kg}$ doses. The right ovaries of the mice were removed, weighed, and fixed in $4 \%$ paraformaldehyde at $4^{\circ} \mathrm{C}$ overnight. The fixed ovaries were passed through the alcohol series, cleaned with xylene, and embedded in paraffin blocks. Consequently, $5-\mu \mathrm{m}$-thick sections were cut out from the ovarian blocks for histomorphological analyses.

\section{Crossman's triple stain and morphological classification of the follicles}

For the histological studies, $5-\mu \mathrm{m}$-thick sections were cut from the paraffin blocks, mounted on slides, and dried overnight. After dewaxing and rehydration, the sections were used for Crossman's triple staining to expose ovarian morphology. The classification of the ovarian follicles was performed based on the criteria reported earlier by Wang et al. [31]. When the oocyte was surrounded by a layer of flat granulosa cells, the ovarian follicle was classified as primordial follicle (Fig. 1A), when the oocyte was encircled by a layer of cubic granulosa cells, the ovarian follicle was classified as a primary follicle (Fig. 1B); on the other hand, when the oocyte was bordered by two or three layers of cubic granulosa cells but lacking an antral follicle, the ovarian follicle was classified as a secondary follicle (Fig. 1C), finally the ovarian follicle containing more than four layers of granulosa cells with one or more antral spaces, or with the cumulus granulosa cell layer was classified as a tertiary follicle (Fig. 1D) [31]. Based on the criteria de-
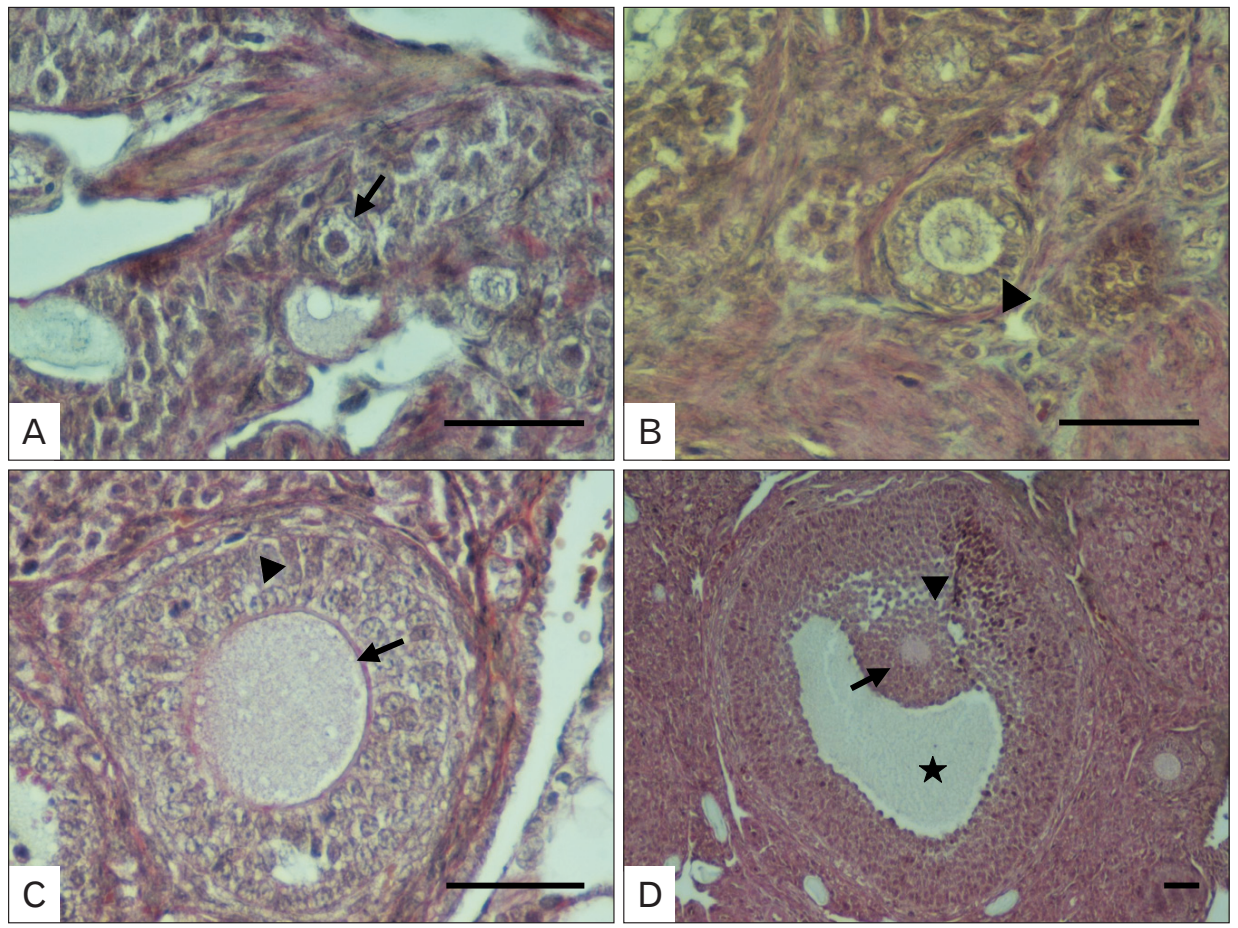

Fig. 1. Classification of follicles in ovarian sections. (A) Note the primordial follicle and single-layered of flat granulosa cells surrounding the primordial oocytes (arrow). (B) Observe the primary follicle and the single-layered cubic granulosa cells around the oocyte (arrowhead). (C) Notice the secondary follicle and the multi-layered cubic granulosa cells neighboring the oocytes (arrowhead) and zona pellucida (arrow). (D) Note the Graafian follicle with C-shaped antrum (star), cumulus oophorous (arrowhead), and stratum granulosum (arrow). Scale bars $=50 \mu \mathrm{m}$. 
scribed here, the sections were examined under light microscope and the follicles were classified accordingly.

\section{Stereological analyses}

Stereological data were obtained using systematic random sampling method at each stage to apply unbiased principles. Point-count analysis was used to calculate total ovarian volume while Stereoinvestigator software (MBF Bioscience, Ankara, Turkey) was used to determine ratio of the ovarian cortex to its medulla (Vv) (Fig. 2). For calculating the diameters of the primordial, primary, secondary, and tertiary follicles; the longest axes of the follicles were determined as major diameter (a), the other axis intersecting the major axis and passing through the midpoint of the follicles was determined as minor diameter (b). Subsequently, average diameter (d) for the follicles was calculated using the formula $d=\sqrt{ }$ a.b for all the sections via performing around 150-200 measurements from each type of follicle (Fig. 3). Moreover, micrometer was used for the standard of magnitude of the measurements obtained. The point-count method was applied to calculate the ratio of oocyte to granulosa cell layer in the secondary follicles.

Total ovarian volume and ratio of ovarian cortex to ovarian medulla were calculated using Cavalieri method as described previously [32]. For this purpose, a total of 12 sections were examined from each ovarian block. The sections were examined using the point grid application in which the points that

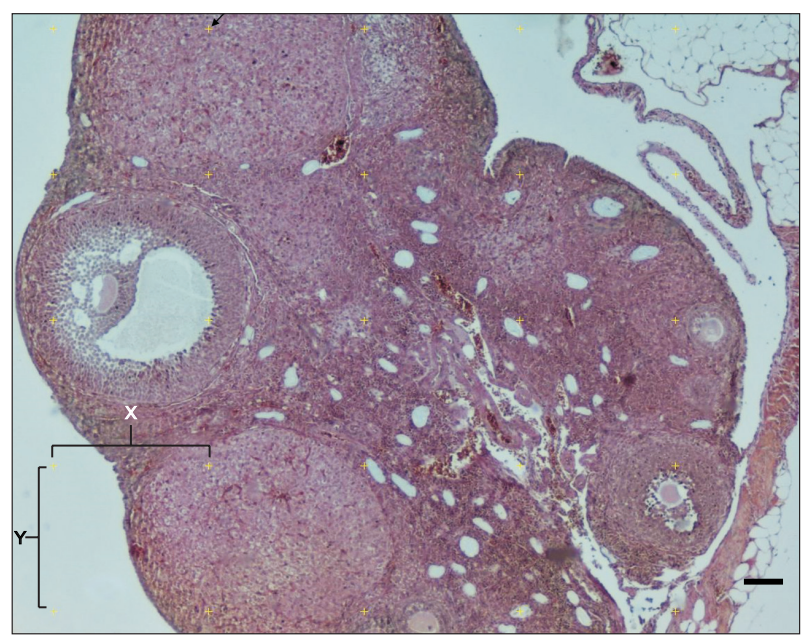

Fig. 2. Calculation of the total volume and cortex to medulla ratio of the ovary of mice using point-count method. Between two plus signs on the horizontal and vertical axis, defined as ' $\mathrm{X}$ ' and ' $\mathrm{Y}$ ', the tissue falling into the right-top corner of the counting Point Grid was included in the counting (arrow). Scale bar $=100 \mu \mathrm{m}$. fall on the examined region on the tissue were considered for assessment. The following formula was used for the evaluation of the data obtained:

$$
\begin{aligned}
& \mathrm{V}(\mathrm{ref})=\mathrm{At} \\
& \mathrm{A}=\mathrm{a}(\mathrm{p}) \sum \mathrm{P}_{\mathrm{i}}
\end{aligned}
$$

, where, $\mathrm{t}=$ cross-sectional thickness, $\Sigma \mathrm{Pi}=$ the total number of points per cortex and medulla, $\mathrm{a}(\mathrm{p})$ denotes the plane distance between $\mathrm{X}$ and $\mathrm{Y}$, the arrow to the right of the plus sign is considered.

\section{Ethics statement}

Animal study was carried out in accordance with the recommendations in the Guide for the Care and Use of Experimental Animals Ethics Committee of Eskişehir Osmangazi University (EAEC-ESOGU). The protocols used were approved by the Committee on the Ethics of Animal Experiments of Medical and Experimental Research Center of ESOGU. Institutional Ethical committee number under which this study has been approved was 401-1. The mice were sacrificed by cervical dislocation under anesthesia with minimum suffering.

\section{Statistical analyses}

Statistical analyses were performed using the IBM SPSS version 21 (IBM Corp., Armonk, NY, USA). Shapiro-Wilk Normality Test was used to determine whether the groups possessed normal distribution. Since the groups showed normal distribution, they were further analyzed using inde-

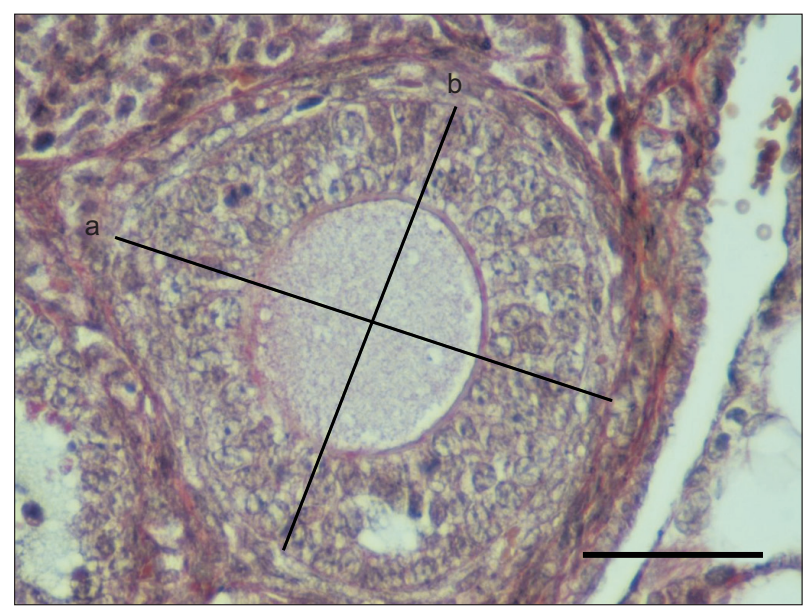

Fig. 3. The calculation of follicular diameter. Measurement of long (a) and short diameter (b) in secondary follicle. Scale bar $=50 \mu \mathrm{m}$. 
pendent $t$-test. The results were accepted as $95 \%$ confidence interval and those with a $P$-value less than 0.05 were considered to be statistically significant. The results were expressed as mean \pm SD.

\section{Results}

All the mice used in the present study completed a 9-week feeding cycle in a healthy manner. They did not have tumors or any abnormal tissue in their bodies. The mice fed with HFD gained more weight and observed to be slower to move than the control group. On the other hand, the mice in the control group were found to move faster and their body weights were within the range appropriate for the average of the ages.

\section{Body weights and intraperitoneal fat tissue}

No meaningful difference in body weights of the mice was observed between the experimental and control groups prior to the feeding period with different diets. The average body weight for the animals was $28.62 \pm 2.34 \mathrm{~g}$. After a 9-week feeding period, while the average body weights of the animals in the experimental group was $34.12 \pm 3.13 \mathrm{~g}$, the average body weight of the animals in the control group was $29 \pm 3.16 \mathrm{~g}$. Body weight of the mice in HFD group markedly increased compared to the control group $(P=0.008)$ (Fig. 4A).

At the end of the experimental procedure, intraperitoneal fat tissue was removed from the mice and weighed. Significantly more fat tissue was detected in the HFD group compared to the control group $(P<0.001)$ (Fig. 4B).
A

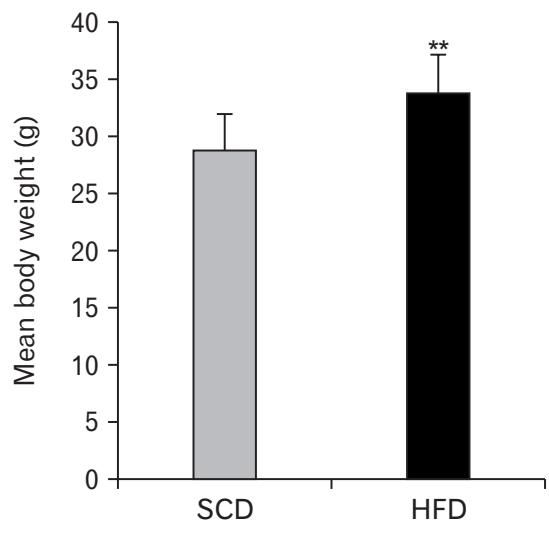

D

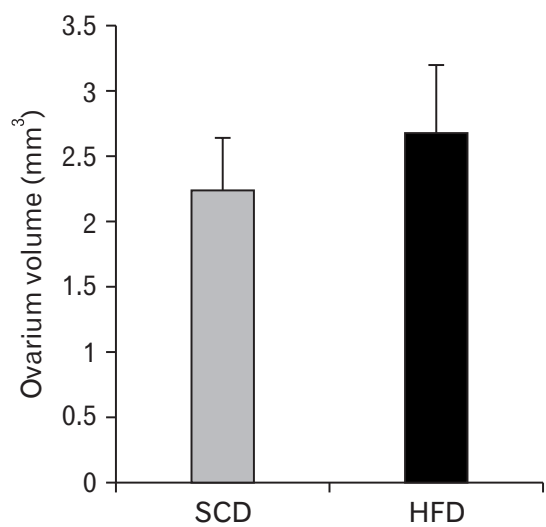

B

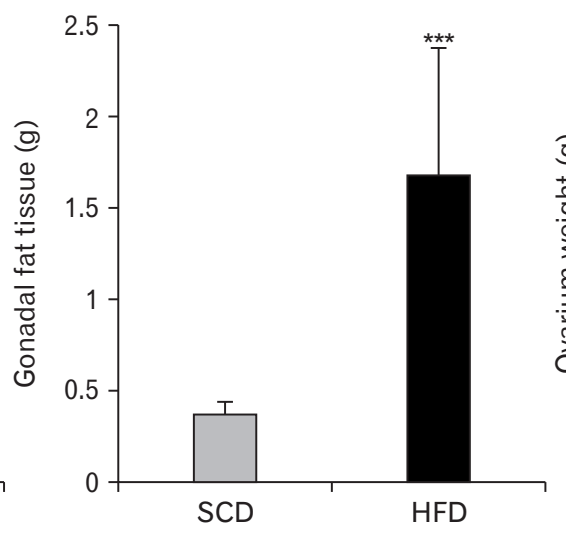

E

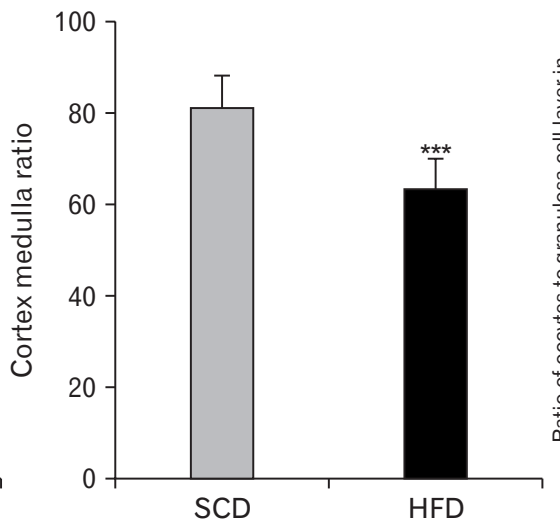

C
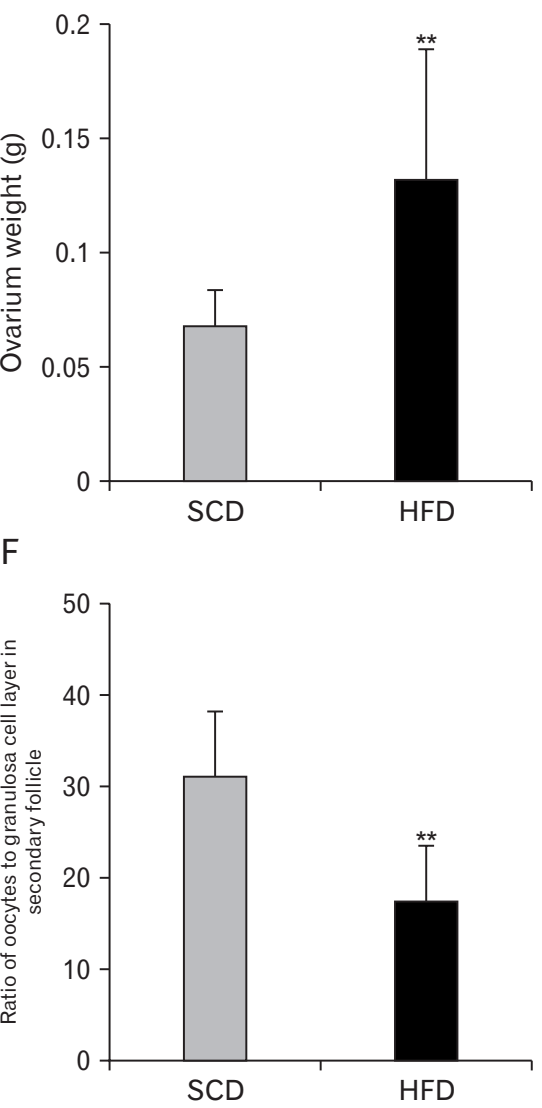

Fig. 4. Metabolic parameters and follicular changes in ovaries of the rats fed on a high-fat diet. The average body weight (A) and Gonadal adipose tissue (B) were measured at the end of the nine-week diet period. The total weight of the ovary (C), its total volume (D) and cortex to medulla ratio (E) were calculated using the Cavalier method. In addition, the ratio of oocytes to granulosa cell layer in secondary follicle (F) was measured using point counting method. Data are presented as means $\pm S D$. ${ }^{* *} P<0.01$ and ${ }^{* * *} P<0.001$ compared to chow group as determined by an independent $T$ test. Standard chow diet (SCD; $n=8)$, high-fat $\operatorname{diet}(n=8)$. 


\section{Ovarian weight}

Ovarian weights for the mice in the control and experimental groups were obtained. While the mean weight of ovary in the experimental group was $131.00 \pm 0.56 \mathrm{mg}$, it was $68.00 \pm 0.14 \mathrm{mg}$ in the control group $(P=0.009)$ (Fig. $4 \mathrm{C})$. The increase in ovarian weight is thought to be associated with an increase in body weight.

\section{Ovarian volume and ratio of ovarian cortex to ovarian medulla}

The Cavalieri method was used to determine the total volume of the ovary and magnification was calculated as 30 . The distance between the two points on the grid was $0.16 \mathrm{~mm}^{2}$. Via applying the formula $\mathrm{V}(\mathrm{ref})=\mathrm{At}$, while the mean volumes of the ovary of the mice fed with HFD were found to be $2.67 \pm 0.52 \mathrm{~mm}^{3}$, it was $2.22 \pm 0.41 \mathrm{~mm}^{3}$ for the ovary of mice fed with standard chow diet. Overall, there was no significant difference between the two groups with regard to mean volumes of the ovary $(P>0.05)$ (Fig. 4D).

The point counting method was used to calculate the volume of the ovarian cortex and medulla. The ratio between the cortex and medulla was calculated using Vv cortex/medulla formula. While the ratio was $81.96 \pm 6.62$ in the control group, it was $64.12 \pm 6.46$ in the experimental group. The results indicated that cortex to medulla ratio markedly decreased in the experimental group in comparison with the control group $(P<0.001)$ (Fig. 4E).

\section{Number of follicles}

We determined the number of follicles at different stages of the development in the mouse ovary after the 9 weeks of diet period to evaluate the effect of HFD on their number and developmental morphology. Counting and staging of the follicles were performed through evaluating the histology of the ovaries collected from the control group (Fig. 5A) and HFD group (Fig. 5B) at low magnifications. We classified follicular development as primordial follicle, primary follicle, secondary follicle, tertiary follicle, atrietic follicle and corpus luteum. The number of primordial follicles significantly decreased in the mice fed on HFD compared to the control group. While the number of primordial follicles was $1,558.75 \pm 98.61$ in the control group, it was $521.00 \pm 71.42(P<0.001)$ in the experimental group (Fig. 6A). Moreover, while the number of primary follicles was $123.63 \pm 24.20$ in the control group, it was $151.57 \pm 24.57(P=0.004)$ in the experimental group (Fig. $6 \mathrm{~B})$. Similarly, while the number of secondary follicles was $76.75 \pm 1.66$ in the control group, it was 88.86 $\pm 9.06(P=0.003)$ in the experimental group (Fig. $6 \mathrm{C}$ ). The number of tertiary follicles increased from $14.00 \pm 1.06$ in the control group to $32.86 \pm 2.47(P<0.001)$ in the experimental group (Fig. 6D). Likewise, while the number of atrial follicles was $97.63 \pm 7.44$ in the control group, it was $152.71 \pm 6.29(P<0.001)$ in the experimental group (Fig. 6E). Moreover, atretic follicles were also classified based on stages of the follicles (Fig. 6H). In control group; of the atretic follicles, $24.38 \% \pm 4.87 \%$ were primordial, $2.68 \% \pm 2.74 \%$ primary, $10.12 \% \pm 1.04 \%$ secondary and $5.54 \% \pm 2.38 \%$ tertiary follicles. In HFD group, of the atretic follicles, $74.08 \% \pm 4.32 \%$ were primordial, $20.12 \% \pm 2.70 \%$ primary, $12.44 \% \pm 3.84 \%$ secondary and $8.26 \% \pm 1.06 \%$ tertiary follicles. Finally, while the number of corpus luteum was $16.13 \pm 1.35$ in the control group, it was $21.86 \pm 1.77(P<0.001)$ in the experimental group (Fig. 6F).

\section{Diameters of follicles}

Primordial, primary, secondary and tertiary follicle diameters in the mice fed with normal and HFDs were measured using stereological methods. The longest axis of the follicles was identified as major diameter (a), and the other axis passing through the midline of the major axis was identified as minor diameter (b); subsequently, diameters of the follicles were
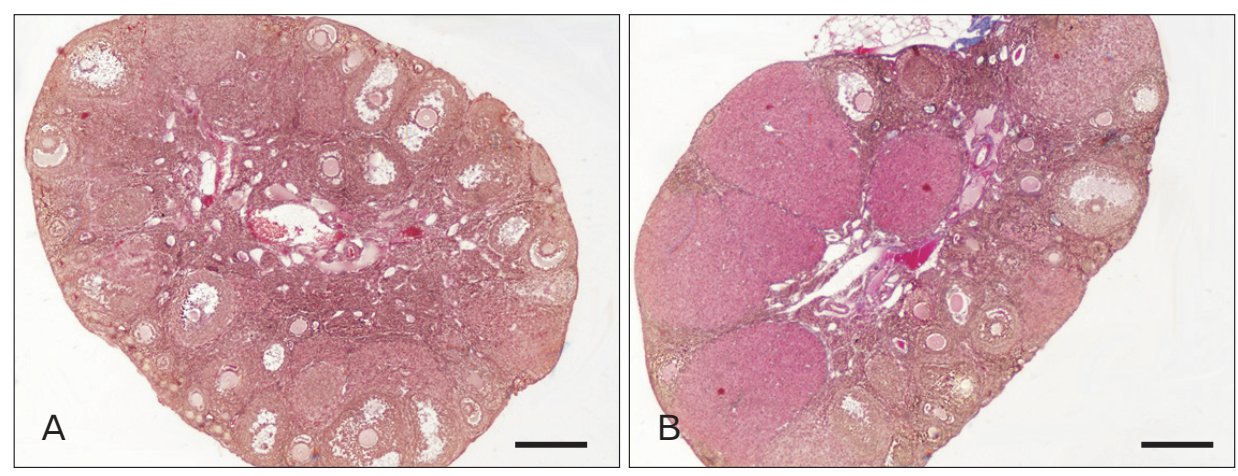

Fig. 5. Low magnifications of ovarian histology from control (A) and high-fat $\operatorname{diet}(B)$ groups. Scale bars $=100 \mu \mathrm{m}$. 
A

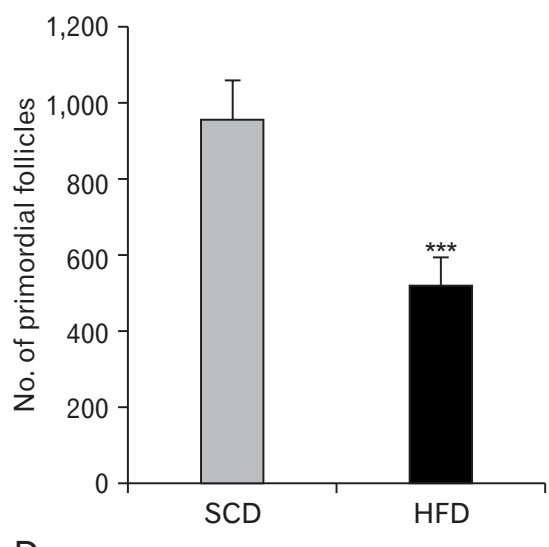

D

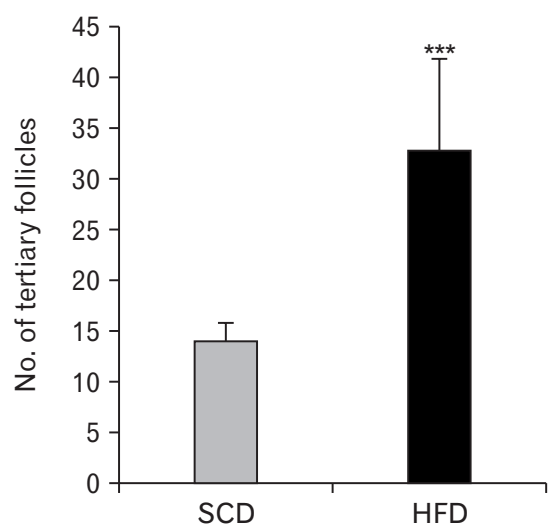

G

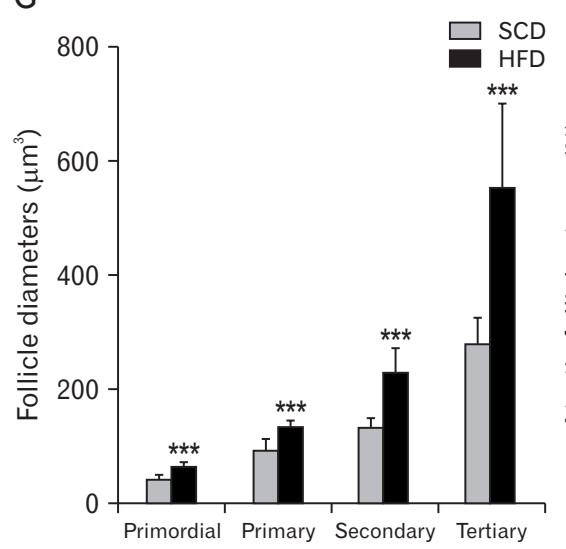

B

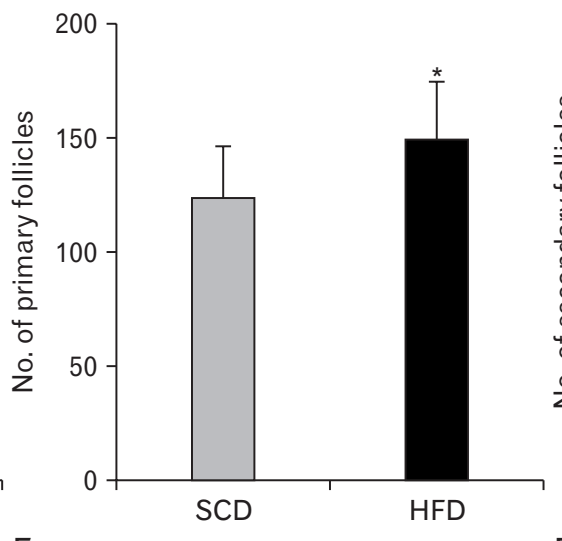

E

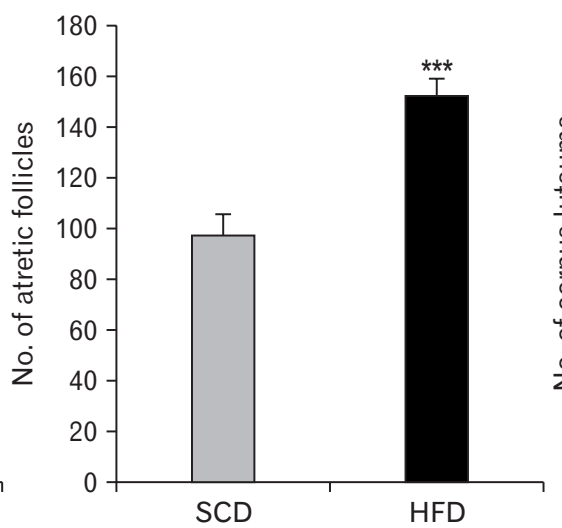

$\mathrm{H}$

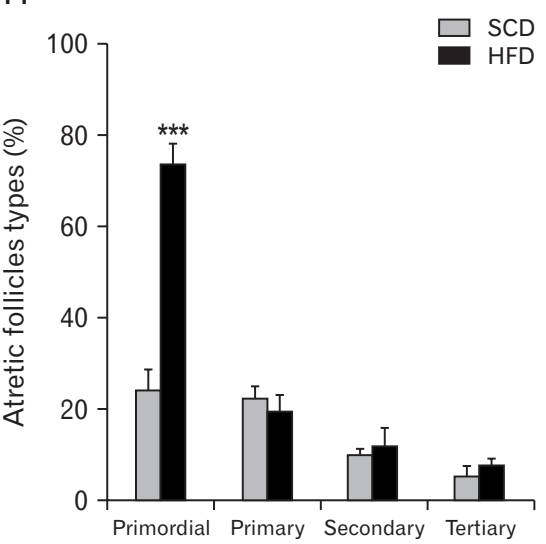

C

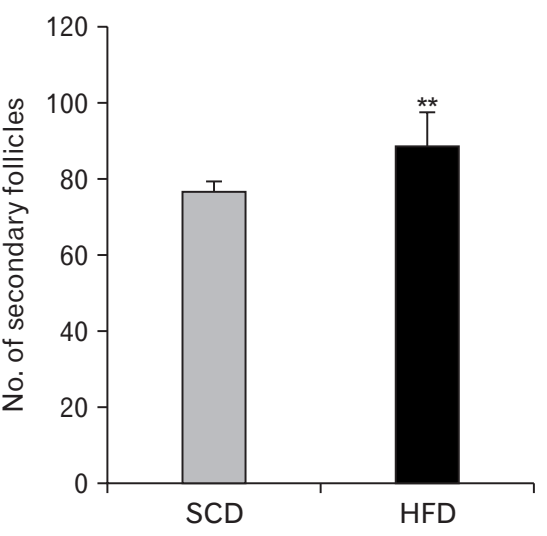

F

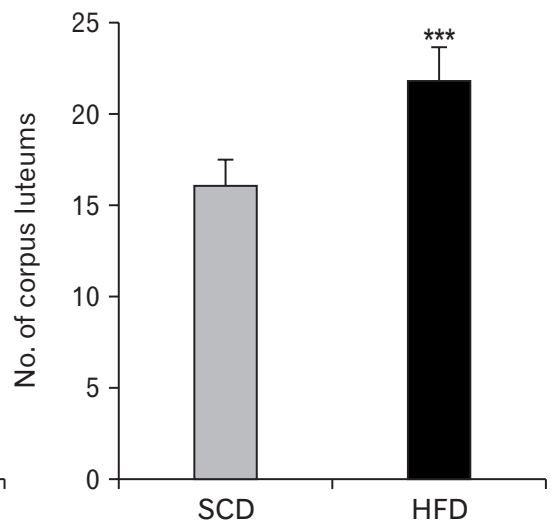

Fig. 6. Comparison of numbers of primordial (A), primary (B), secondary (C), tertiary (D), and atretic follicles (E) in addition to number of corpus luteum $(F)$, follicle diameters $(G)$, and percentage of atretic follicle types $(H)$ in high-fat diet $(H F D)$ and control groups. Note that the data are presented as mean \pm SD. ${ }^{*} P<0.05,{ }^{* *} P<0.01$, and ${ }^{* * *} P<0.001$ compared to control group as determined by an independent $t$-test. Standard chow $\operatorname{diet}(\mathrm{SCD} ; \mathrm{n}=8), \operatorname{HFD}(\mathrm{n}=8)$.

determined using the major and minor diameters identified (Fig. 6G). While the mean primordial follicle diameter was $43.48 \pm 6.92 \mu \mathrm{m}$ in the control group, it was $64.776 \pm 9.55 \mu \mathrm{m}$ in the experimental group. The difference between the two groups was statistically significant $(P<0.05)$. Likewise, while the mean primary follicle diameter in the control group was $90.42 \pm 23.34 \mu \mathrm{m}$, it was $133.79 \pm 13.48 \mu \mathrm{m}$ in the experimental group. The difference in mean primary follicle diameter between the two groups was statistically meaningful $(P<0.05)$. Similarly, the mean diameter of the secondary follicle was 
$132.67 \pm 17.67 \mu \mathrm{m}$ in the control group and $227.96 \pm 43.82 \mu \mathrm{m}$ in the experimental group. The difference in the mean diameter of the secondary follicles between the groups was statistically substantial $(P<0.05)$. Ultimately, while the mean tertiary follicle diameter in the control group was $280.49 \pm 50.29 \mu \mathrm{m}$, it was $549.79 \pm 150.88 \mu \mathrm{m}$ in the experimental group. The difference in the mean tertiary follicle diameters between the two groups was statistically momentous $(P<0.05)$. Overall, HFD intake in mice markedly increased diameters of the primordial, primary, secondary and tertiary follicles.

\section{Ratio of oocyte in the secondary follicle to granulosa cell layer}

The point-count method was applied to calculate the ratio of oocyte to granulosa cell layer in the secondary follicles. The granulosa cell layer resided around the oocyte in the secondary follicle is shown to be thicker in the mice fed on with HFD. Consistently, in the present study, the ratio of oocyte to granulosa cell layer was $31.23 \pm 7.16$ in the control group and $17.60 \pm 5.93$ in the experimental group. The difference between the two groups was statistically significant $(P=0.002)$ (Fig. 4F).

\section{Discussion}

Excessive energy intake with high fat containing diets along with reduced physical activity and a more sedentary life has led to a substantial increase in the incidence of obesity around the world. Subsequently, numerous studies indicate that increased incidence of obesity has caused many metabolic diseases from systemic malfunctions to reproductive disorders. Obesity is shown to reduce percentage of the pregnancy among the women through triggering abdominal fat accumulation and decreasing ovulation rates [33]. Consequently, studies concerning the negative effects of obesity on fertilization have gained more importance in recent years.

In the present study, we examined morphological changes in ovaries of the mice fed with HFD for 9 weeks. The current study is the first one stereologically evaluating how feeding of mice with HFD changes ovarian weight, volume, ratio of cortex to medulla, number of follicles and their diameters in addition to alterations occurring in granulosa cell layer shown to be effective in mechanisms leading to formation of PCOS. We think that presence of the ovarian follicles with normal size and diameter is a significant indicator for continuing healthy menstrual activity. A previous study by Karbalay-Doust et al.
[34] emphasizes that any changes in follicular diameter and surface of the follicles thwart the entry of the sperm.

On the other hand, at their work Sohrabi et al. (2015) [17] reported no significant increase in the bodyweight of the mice fed with similar high energy diet for 12 weeks; however, in the present study we fed mice with HFD for 9 weeks and observed marked increase in the bodyweight and intraperitoneal fat tissue, indicating that the current model of feeding mice with the HFD we used here is effective for making the animals suitable for obesity studies. Present findings suggest that increase in weight of the ovary in the mice fed with HFD is due to an increase in their body weight. Although there are studies available on the effect of the androgenic anabolic steroids concerning ovary volume and ratios of cortex to medulla volumes, few or no studies are available regarding the effect of HFD on the volume of the ovarian tissue, the number of follicles at different stages of the development [32, 34]. While we noted no marked increase in the total volume of the ovary, there was a significant increase in ratios of cortex to medulla in the ovaries of the mice fed with HFD. We think that the increase in volume of the cortex is due to increase in number and diameters of the cortical follicles in addition to development of corpus luteum and transformation of follicles to ovarian cysts.

The present results showed that while the number of primordial follicles decreased, the number of primary, secondary and tertiary follicles increased in the obese mice fed with HFD. Therefore, these findings suggest that the obesity induced by HFD causes follicular maturation; however, it increases rate of follicular loss by reducing the number of primordial follicles. Obesity might interfere with follicular development through mammalian target of rapamycin (mTOR), which is a serine/threonine kinase that regulates cell growth and proliferation in response to stress, nutrients, and growth factors [35]. A recent study indicates that obesity interferes with follicular development through mTOR activation and sirtuin 1 inhibition, thereby leading to overactivation of primordial follicles and increasing number of developing and mature follicles. Consequently, overactivation of ovarian follicles might accelerate the rate of follicle loss via promoting follicle apoptosis [31]. Likewise, in their study, Wang et al. [31] suggest that obesity leads to a marked increase in the number of atretic follicles through triggering follicular apoptosis. Moreover, increase in the number of corpus luteum, one of the most important indicators of cystic transformation, indicates that obese animals are prone to development of PCOS 
and likely to experience infertility problems.

Furthermore, diameters of the primordial, primary, secondary, and tertiary follicles were distinctly increased in the ovaries of the mice fed with HFD when compared to the control group fed with standard diet. Particularly, present stereological examinations of the granulosa cell layers in the secondary follicles indicate that follicular cysts are likely to develop at this stage. Granulosa cells form a couple of layers and play an important role in the growth of follicles, in the survival and ovulation of oocytes. Therefore, deterioration of ovarian functional activity may have a significant effect on reproductive capacity [36]. Granulosa cells are thought to contain various growth factors effective in production of sex steroids and stimulation of oocyte development as well. Moreover, follicle-stimulating hormone not only stimulates granulosa cells but also it induces generation of sex steroids through converting estradiol to androgens [37]. However, after ovulation, granulosa cells turn into granulosa lutein cells that produce progesterone [32]. Consequently, our observations imply that the increase in layer of granulosa cells and the development of follicular cysts, which is among the causes of infertility, occurs concomitantly.

In conclusion, the results of the present study indicate that diet-induced obesity harmfully affects fertility through impairing ovarian morphology, weakening follicular development and differentiation, and ultimately leading to decrease in the number of fertile ovum.

\section{ORCID}

Gören Hilal: https://orcid.org/0000-0002-3408-0155

Topal Fatma: https://orcid.org/0000-0003-3491-4970

Yücel Ferruh: https://orcid.org/0000-0002-1238-1483

Güler Sabire: https://orcid.org/0000-0002-7367-6859

Aydar Yüksel: https://orcid.org/0000-0002-0285-9914

\section{Author Contributions}

Conceptualization: AY. Data acquisition: GH, TF, GS. Data analysis or interpretation: TF, YF, GS, AY. Drafting of the manuscript: GH, AY. Critical revision of the manuscript: YF. Approval of the final version of the manuscript: all authors.

\section{Conflicts of Interest}

No potential conflict of interest relevant to this article was reported.

\section{Acknowledgements}

The present study was also financially supported by Eskişehir Osmangazi University Research Projects Center with the project code 2014-586.

\section{References}

1. World Health Organization. Obesity and overweight: fact sheet no 311 [Internet]. Geneva: World Health Organization [cited 2018 Mar 26]. Available from: https://www.who.int/en/newsroom/fact-sheets/detail/obesity-and-overweight.

2. Mayes JS, Watson GH. Direct effects of sex steroid hormones on adipose tissues and obesity. Obes Rev 2004;5:197-216.

3. Balasubramanian P, Jagannathan L, Mahaley RE, Subramanian M, Gilbreath ET, Mohankumar PS, Mohankumar SM. High fat diet affects reproductive functions in female diet-induced obese and dietary resistant rats. J Neuroendocrinol 2012;24:748-55.

4. Morrison JA, Barton B, Biro FM, Sprecher DL, Falkner F, Obarzanek E. Sexual maturation and obesity in 9- and 10-year-old black and white girls: the National Heart, Lung, and Blood Institute Growth and Health Study. J Pediatr 1994;124:889-95.

5. Garn SM, LaVelle M, Pilkington JJ. Comparisons of fatness in premenarcheal and postmenarcheal girls of the same age. J Pediatr 1983;103:328-31.

6. Adair LS, Gordon-Larsen P. Maturational timing and overweight prevalence in US adolescent girls. Am J Public Health 2001;91: 642-4.

7. Dunger DB, Ahmed ML, Ong KK. Effects of obesity on growth and puberty. Best Pract Res Clin Endocrinol Metab 2005;19:37590.

8. Grodstein F, Goldman MB, Cramer DW. Body mass index and ovulatory infertility. Epidemiology 1994;5:247-50.

9. Pandey S, Bhattacharya S. Impact of obesity on gynecology. Womens Health (Lond) 2010;6:107-17.

10. Koning AM, Kuchenbecker WK, Groen H, Hoek A, Land JA, Khan KS, Mol BW. Economic consequences of overweight and obesity in infertility: a framework for evaluating the costs and outcomes of fertility care. Hum Reprod Update 2010;16:246-54.

11. Booth PJ. Metabolic influences on hypothalamic-pituitary-ovarian function in the pig. J Reprod Fertil Suppl 1990;40:89-100.

12. Kruip TA, Kemp B. Nutrition and fertility in agricultural domestic animals. Tijdschr Diergeneeskd 1999;124:462-7.

13. Mitchell M, Armstrong DT, Robker RL, Norman RJ. Adipokines: implications for female fertility and obesity. Reproduction 2005; 130:583-97.

14. Ramlau-Hansen CH, Thulstrup AM, Nohr EA, Bonde JP, Sorensen TI, Olsen J. Subfecundity in overweight and obese couples. Hum Reprod 2007;22:1634-7.

15. van der Steeg JW, Steures P, Eijkemans MJ, Habbema JD, 
Hompes PG, Burggraaff JM, Oosterhuis GJ, Bossuyt PM, van der Veen F, Mol BW. Obesity affects spontaneous pregnancy chances in subfertile, ovulatory women. Hum Reprod 2008;23:324-8.

16. Popkin BM, Doak CM. The obesity epidemic is a worldwide phenomenon. Nutr Rev 1998;56(4 Pt 1):106-14.

17. Sohrabi M, Roushandeh AM, Alizadeh Z, Vahidinia A, Vahabian M, Hosseini M. Effect of a high fat diet on ovary morphology, in vitro development, in vitro fertilisation rate and oocyte quality in mice. Singapore Med J 2015;56:573-9.

18. Brewer CJ, Balen AH. The adverse effects of obesity on conception and implantation. Reproduction 2010;140:347-64.

19. Ogden CL, Carroll MD, Fryar CD, Flegal KM. Prevalence of obesity among adults and youth: United States, 2011-2014. NCHS Data Brief 2015;(219):1-8.

20. Broekmans FJ, Knauff EA, Valkenburg O, Laven JS, Eijkemans MJ, Fauser BC. PCOS according to the Rotterdam consensus criteria: change in prevalence among WHO-II anovulation and association with metabolic factors. BJOG 2006;113:1210-7.

21. Shi D, Vine DF. Animal models of polycystic ovary syndrome: a focused review of rodent models in relationship to clinical phenotypes and cardiometabolic risk. Fertil Steril 2012;98:185-93.

22. Padmanabhan V, Veiga-Lopez A. Animal models of the polycystic ovary syndrome phenotype. Steroids 2013;78:734-40.

23. Wu S, Divall S, Nwaopara A, Radovick S, Wondisford F, Ko C, Wolfe A. Obesity-induced infertility and hyperandrogenism are corrected by deletion of the insulin receptor in the ovarian theca cell. Diabetes 2014;63:1270-82.

24. Newell-Fugate AE, Taibl JN, Clark SG, Allosh M, Sturek M, Krisher RL. Effects of diet-induced obesity on metabolic parameters and reproductive function in famele Ossabaw minipigs. Comp Med 2014;64:44-9.

25. Jungheim ES, Schoeller EL, Marquard KL, Louden ED, Schaffer JE, Moley KH. Diet-induced obesity model: abnormal oocytes and persistent growth abnormalities in the offspring. Endocrinology 2010;151:4039-46.

26. Dokras A, Baredziak L, Blaine J, Syrop C, VanVoorhis BJ, Sparks A. Obstetric outcomes after in vitro fertilization in obese and morbidly obese women. Obstet Gynecol 2006;108:61-9.

27. Minge CE, Bennett BD, Norman RJ, Robker RL. Peroxisome proliferator-activated receptor-gamma agonist rosiglitazone reverses the adverse effects of diet-induced obesity on oocyte quality. Endocrinology 2008;149:2646-56.

28. Skaznik-Wikiel ME, Swindle DC, Allshouse AA, Polotsky AJ, McManaman JL. High-fat diet causes subfertility and compromised ovarian function independent of obesity in mice. Biol Reprod 2016;94:108.

29. National Institute for Health and Care Excellence. Assessment and treatment for people with fertility problems (NICE clinical guideline 156). London: National Institute for Health and Care Excellence; 2013.

30. Sorensen LB, Soe M, Halkier KH, Stigsby B, Astrup A. Effects of increased dietary protein-to-carbohydrate ratios in women with polycystic ovary syndrome. Am J Clin Nutr 2012;95:39-48.

31. Wang N, Luo LL, Xu JJ, Xu MY, Zhang XM, Zhou XL, Liu WJ, Fu YC. Obesity accelerates ovarian follicle development and follicle loss in rats. Metabolism 2014;63:94-103.

32. Noorafshan A, Ahmadi M, Mesbah SF, Karbalay-Doust S. Stereological study of the effects of letrozole and estradiol valerate treatment on the ovary of rats. Clin Exp Reprod Med 2013;40: 115-21.

33. ESHRE Task Force on Ethics and Law, Dondorp W, de Wert G, Pennings G, Shenfield F, Devroey P, Tarlatzis B, Barri P. Lifestylerelated factors and access to medically assisted reproduction. Hum Reprod 2010;25:578-83.

34. Karbalay-Doust S, Noorafshan A. Stereological estimation of ovarian oocyte volume, surface area and number: application on mice treated with nandrolone decanoate. Folia Histochem Cytobiol 2012;50:275-9.

35. Ost A, Svensson K, Ruishalme I, Brannmark C, Franck N, Krook H, Sandstrom P, Kjolhede P, Stralfors P. Attenuated mTOR signaling and enhanced autophagy in adipocytes from obese patients with type 2 diabetes. Mol Med 2010;16:235-46.

36. Hussein MR. Apoptosis in the ovary: molecular mechanisms. Hum Reprod Update 2005;11:162-77.

37. Garzo VG, Dorrington JH. Aromatase activity in human granulosa cells during follicular development and the modulation by follicle-stimulating hormone and insulin. Am J Obstet Gynecol 1984;148:657-62. 